\title{
Food Safety Knowledge, Attitude, and Practice of University Students, KPK Pakistan, 2019: A Cross-Sectional Study
}

Junaid Ahmad', Shahzeb Javed², Mehmood Khan', Shadman', Muhammad Farooq ${ }^{3 *}$, Muhammad Saleem 4 , Rahila Afzal ${ }^{5}$, Muhammad Aasim ${ }^{6}$, Naqeeb Ullah ${ }^{7}$, Muhammad Noman Khan ${ }^{8}$, Dawood ${ }^{8}$ and Naila Ilyas ${ }^{9}$

${ }^{1}$ Hazara University Mansehra, Khyber Pakhtunkhwa, Pakistan; ${ }^{2}$ Abbottabad University of Science and Technology, Khyber Pakbtunkbwa, Pakistan; ${ }^{3}$ College of Food Science and Engineering, Northwest A and F University, Yangling, Shaanxi 712100, PR China; ${ }^{4}$ Assistant Director Food District Mastung, Balochistan, Pakistan; ${ }^{5}$ Assistant Director Food, Food Directorate Quetta, Balochistan, Pakistan; 'Soil and Environmental Sciences, The University of Agriculture Peshawar, Khyber Pakbtunkbwa, Pakistan; ${ }^{7}$ Department of Agronomy, University of Agriculture Faisalabad, Pakistan; ${ }^{8}$ Department of Agronomy, University of Agriculture Peshawar, Khyber Pakhtunkhwa, Pakistan; ${ }^{9}$ Graduate School of Chinese Academy of Agricultural Sciences, Beijing 100081, China.

Abstract | Food safety and cleanliness are becoming increasingly important in Pakistan, as new incidences of food contaminants emerge, which, if overlooked, can result in a variety of health risks, illness, outbreaks, and even death. The goal of this study was to look at the students' knowledge, attitudes, and practices on food safety and cleanliness at a different institution in KPK, Pakistan. A cross-sectional study was done among 1000 government and private university students in KPK, Pakistan, using a self-administered, pre-tested questionnaire with a total of 26 questions. Self-administered survey forms were used to collect data from several disciplines. Every correct and incorrect response was given a score of yes or no in order to assess the knowledge. For the purposes of assessing Attitude and Practice, each correct response received a score of (yes), a neutral response received a score of (don't know), and an erroneous response received a score of (No). For each component, quartiles were created. Knowledge, attitude, and practice were categorized into adequate and insufficient quartiles based on quartiles. Males made up 74.44 percent of the study participants, while females made up 25.55 percent. Postgraduate courses accounted for $29 \%$ of participants, while undergraduate courses accounted for 71.1 percent. 35.86 percent of participants had appropriate knowledge, 52.41 percent had adequate attitude, and 47 percent had acceptable practice when it came to food safety and hygiene. In the near future, continuous education is required to raise awareness among young adults; they will be the ones directly handling food and will play a key role in helping to maintain a sanitary and clean environment.

Received | June 11, 2021; Accepted | August 26, 2021; Published | November 08, 2021

*Correspondence | Muhammad Farooq, College of Food Science and Engineering, Northwest A and F University, Yangling, Shaanxi 712100, PR China; Email: Farooq.fst28@gmail.com; Shahzeb Javed, Abbottabad University of Science and Technology, Khyber Pakhtunkhwa, Pakistan; Email: shahzebjaved7719@gmail.com

Citation | Ahmad, J., S. Javed, M. Khan, Shadman, M. Farooq, M. Saleem, R. Afzal, M. Aasim, N. Ullah, M.N. Khan, Dawood and N Ilyas. 2021. Food safety knowledge, attitude, and practice of university students, KPK Pakistan, 2019: A cross-sectional study. Journal of Innovative Sciences, 7(2): 281-287.

DOI | https://dx.doi.org/10.17582/journal.jis/2021/7.2.281.287

Keywords $\mid$ Foodborne disease, Food safety, Food hygiene, Knowledge, Attitude, Practice

\section{Introduction}

$\mathrm{S}$ ince the dawn of human history, foodborne diseases (FBDs) have been a global scourge and a global public health burden for all societies. Mallach et al. (2016) and Lam et al. (2013). In both industrialized and developing countries, the burden of this problem varies from one demographic to the next. According 
to the World Health Organization (WHO, 1999), around 600 million people roughly one out of every ten people on the earth become unwell after eating contaminated food, and 420000 people die each year, resulting in the loss of 33 million healthy lifestyles. Similarly, 2.2 million children in poorer countries die of diarrhea each year (Foodborne Disease Outbreaks, 2008). Inadequate sanitation, a lack of drinkable drinking water, insufficient food storage facilities, and a lack of food safety awareness make foodborne disease outbreaks more likely in underdeveloped countries. Food Safety Knowledge and Practice (2009). It is the leading cause of morbidity and mortality all across the world. In many regions of the world, foodborne outbreaks caused by tainted food are becoming more widespread.

Insufficient understanding leads to poor food handling procedures in evaluating food microbiological contamination sold by mobile food managers, according to studies conducted by the Food and Agriculture Organization (2003). Food handlers in various industries can play a significant role in preventing food-borne disease outbreaks. However, in low-income developing nations, a number of factors may contribute to a sufficiently low occurrence of these diseases, altering the rate of foodborne sickness Odeyemi (2016). When food is prepared, served, and consumed as intended, food safety refers to the level of assurance that it will not cause illness or harm to the customer FAO/World Health Organization (2003).

In developing countries, a large amount of readyto-eat food is sold out on the road because of its convenience instead of security, quality, and hygiene. Abdalla et al. (2008). Street foods and restaurants have been linked with numerous food-borne illnesses and food poisoning outbreaks Mensah and Yeboah (2002), Feglo and Sakyi (2012). Since the outbreaks of food toxicity are not investigated in many developing countries, both medically and microbiologically, the role of restaurants as access to cause pathogens remains unclear. Also, Foodborne disease outbreaks occur both at home and in social groups Takeda and Akamatsu (2011). In developing countries, lack of knowledge about food safety, decreasing personal hygiene, improper food handling, and domestic preparation plays a part in foodborne disease outbreaks due to contamination of raw food with food processed Stratev and Odeyemi (2017).
Begin by writing or pasting something here, and then move on to the next step. Food handlers and consumers both have a part in foodborne disease outbreaks caused by inappropriate food handling during preparation, processing, or storage Knowledge (2014) attitudes, and practices. Food handlers who do not exercise basic food safety and personal hygiene during food preparation may become vectors for microbes through their hands, lips, and skin, according to WHO (1999). Many factors have contributed to the frequency of foodborne infections in developing nations, and these diseases can be minimized when properly treated. Common blunders included serving contaminated raw food, cooking/heating food insufficiently, enabling diseased persons to handle implicated food, and exercising poor hygiene (World Health Organization, 1999. In food safety education, it's critical to understand the perspectives of food handless the button.

Hazardous food contains harmful microorganisms such as Salmonella, Campylobacter, and Enterohaemorrhagic Escherichia coli), viruses (Norovirus, Hepatitis A virus), parasites (Echinococcus, or Taenia solium, Ascaris, Cryptosporidium, Entamoeba histolytica, or Giardia), and chemical substances, which can cause more than 200 foodborne diseases ranging from diarrhea to Diarrheal infections are the most common illness caused by ingesting contaminated food; 550 million people get sick and 230000 people die each year. Odeyemi (2016) Food related sickness affects more than $33 \%$ of the population in underdeveloped countries, according to statistics. According to the Office of Disease Prevention and Health Promotion (ODOHP), foodborne infections affect 48 million Northern Americans (about 17 percent of the population in the United States) and result in 128,000 hospitalizations and 3000 deaths WHO (1999).

This issue could be attributed to the low sanitation and hygiene conditions in those countries. Food handling during the preparation method via food handlers, food purchases from hazardous assist, poor cooking or warming, stockpiling at room temperature, cross-contamination of different foods, poor personal hygiene, or inappropriate food handling practices are the primary factors in food infection Odeyemi (2016).

As a result, knowing the cleaning practices connected with food handlers is crucial to minimize foodborne infections. The training and education of food 
handlers working at such roadside eateries could also be a relatively low-cost way to reduce the occurrence of foodborne infection morbidity and death Mensah et al. (2002). The unending and chaotic accumulation of such road food establishments has put great strain on assets like as water, sewage systems, and city infrastructure, causing them to clog and become messy, negatively impacting day-to-day life. In Pakistan, it's critical to first understand current sanitation methods among food handlers working in these canteens so that their current knowledge and practices may be assessed Mensah et al. (2002). The goal of this study was to analyze respondent information on food handling and eating attitudes, cooking practices, and understanding of food safety and hygiene in five different university canteens in Khyber Pakhtunkhwa, Pakistan.

\section{Materials and Methods}

\subsection{Study population and data collection}

From January to June 2019, the study was designed and directed on the campus of five separate colleges in Khyber Pakhtunkhwa, Pakistan, using standardized questionnaires on food handling, eating, cooking practice, and respondents' understanding of food safety. Swabi University Distt Swabi, Abdul Wali Khan University Distt Mardan, University of Haripur University Distt Haripur, Comsats University Distt Abbottabad, and Hazara University Distt Mansehra were among the universities represented at the canteen. The questionnaires were filled out by each respondent and took between 15 and 24 minutes to complete. Questionnaires that were incomplete or incorrectly filled out were dismissed. Out of 1000 structured surveys, only 900 (90 percent) were significant.

\subsection{Designing a questionnaire}

For this inquiry, a self-regulated questioner was arranged based on previous research. There were four sections in the revised surveys. The first section was designed to gather information about the demographic features of the respondents. The second section consists of 15 questions that cover various aspects of food safety and cooking behavior. To reduce the reaction inclination, respondents were asked to choose from three options: yes, no, or don't know. Section three consisted of 14 yes/no/don't know questions all related to food handling and eating technique and attitude. The final section of the survey consisted of ten yes/no/don't know responses to a question assessing respondents' awareness of food sanitation.

\subsection{Analyzing data}

The Social Package for Statistical Analysis (SPSS) version 20 was used to analyses the data collected. In each class, the just mean replies and percentages connected with responses were calculated and tabulated.

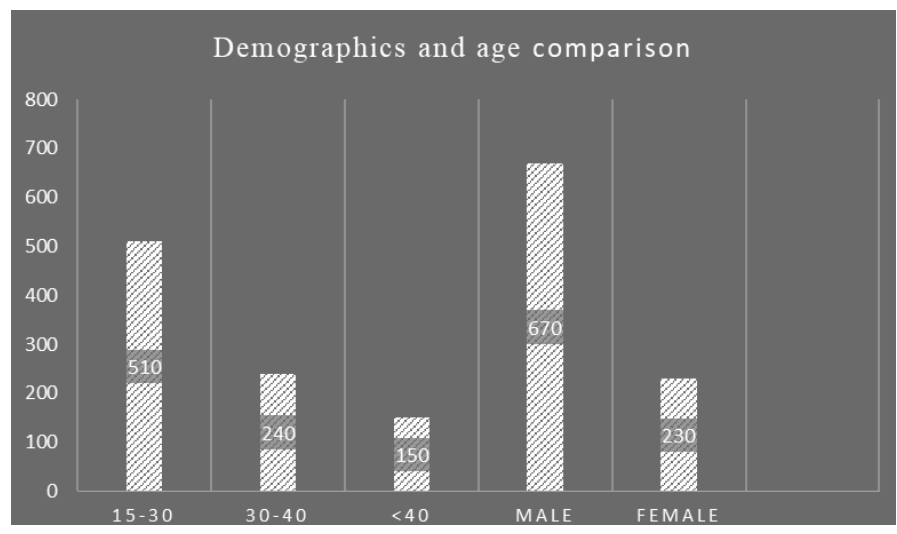

Figure 1: Demographics characteristics and age comparison.

\section{Results and Discussion}

\subsection{Participants' socio-demographic characteristics}

In total, 900 questionnaires were collected.

\subsection{Practices towards food safety}

The overall score for food safety practice was 900 out of 900 . Food safety was practiced better by 34 percent, moderately by 43.50 percent, and poorly by 22.6 percent. Figure 2 illustrates this. 62.22 percent of respondents said they typically wash their hands before preparing or cooking food, while 24.44 percent said they don't wash their hands at all. When confronted with a cut or injury, 55.55 percent of respondents said they continued working, which is a very concerning situation. Only 45 percent, as stated in Figure 2, follow proper requirements (face mask, gloves, etc.) when making food. Only 44.44 percent are certain that they wash their kitchen knives before and after use. $48-88 \%$ of the participants coughed and sneezed near the food, which is quite risky. Only 51.11 percent of people maintain their food surfaces tidy and clean. Separate food storage rooms are found in 66.66 percent of members. Only 15.55 percent of the attendees have completed their food safety training. 48.88 percent said their food preparation and storage areas are well-built and easy to clean. 


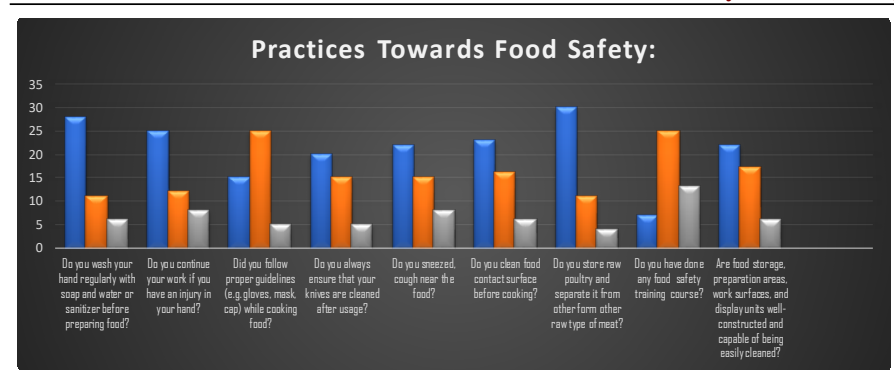

Figure 2: Food safety behavior regarding cooking.

\subsection{Attitude in food safety}

Food safety behavior revealed that more than 65 percent of participants wash their hands before and after handling food, according to Figure 3. However, just $30 \%$ of people are aware that taking routine preventive measures might protect the population from food poisoning. Only half agree that food contamination prevention or safe food handling is a significant component of their job. 65 percent of participants wipe and dry their meals using the same cloth or towel. Only $23 \%$ of the participants used a clean and neat cloth to handle food. Furthermore, 73 percent of people who collect money and serve food with the same hand indicate that they do not wash their hands after serving and collecting food. $80 \%$ of the participants are conversing while serving meals, which is a highly concerning situation.

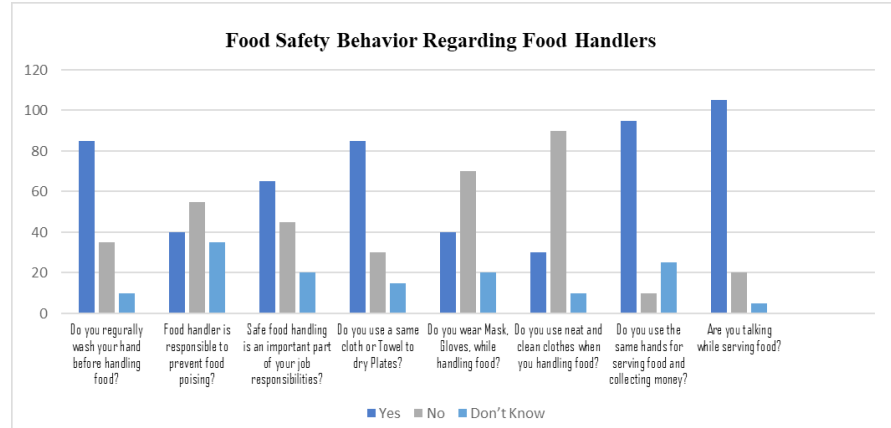

Figure 3: Food safety behavior regarding food handler.

\subsection{Food safety knowledge of the participants}

As mentioned in Figure 4 showed that only 24\% of participants know that food-borne diseases can cause death. Only $31 \%$ of participants agree that raw food is the common source of food poisoning. Among the participants, $48 \%$ agree that if food is looking good it will be safe to eat. Out of $100 \%$, only $37 \%$ know that Food hygienic means to remove the illness-causing factor in food. As mentioned in Figure 4 only $45 \%$ of participants know that if food changes its color, odor, or taste its means food is contaminated. 38\% of participants consider freezing are the best way to prevent food from contamination. 33\% of members know that eating and drinking at the workplace increase the risk of contamination. On average of $26 \%$ did not check the expiry date of the food package before purchasing.

THE KNOWLEDGE OF RESPONDENTS REGARDING FOOD SAFETY

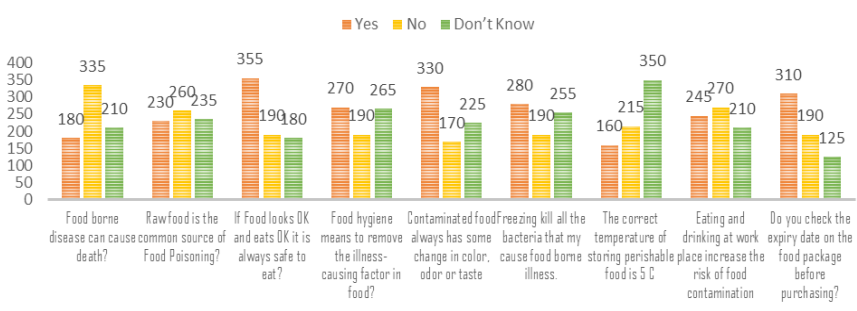

Figure 4: The knowledge of respondents regarding food safety.

The cross-sectional survey found that 35.86 percent of government and private university students in KPK Pakistan had adequate knowledge, 52.41 percent had sufficient attitude, and 47 percent had adequate practice on food safety and cleanliness. A KAP research done among private universities in Kedah state, Malaysia, found that $34 \%$ of students had good/positive knowledge Abdul Nazer Ali, Angelin. Likewise, a study conducted by Hassan and Dimassi revealed, contrary results too compared to ours regarding food safety knowledge Hussein and Dimassi (2014). While comparing our study with those of Taif University students the score of attitudes was less at 53\% having positive attitude regarding food safety and hygiene Labib and Al-Malkhi (2010). Based on research conducted in Turkey In contrast to our 46.6 percent accurately replying, $78.9 \%$ knew that raw poultry, fish, and beef should not come into touch with each other Aluh et al. (2019) International Journal of Adolescent Medicine and Health (2019). According to our practice score, it was 52.41 percent, indicating that despite good/positive knowledge and attitude toward food safety and hygiene, practice among university students remains inadequate. In comparison to another study conducted by Aluh et al. (2019), Adolescents in secondary rural schools in Nigeria practiced good/positive food hygiene, with a mean score of 82.48 percent and more than half of the respondents practicing good/positive food hygiene (54.4 percent) Nevins (2003). Regarding the practice of tasting food to ascertain if it's safe to consume or not, according to a study conducted in Turkey, $46.6 \%$ tasted food to check its safety, which is contrary to our score of 22\% (4). A study conducted in Bulgaria found 
that people had good/positive food safety knowledge, which is similar to the findings of our study Stratev et al. (2017. Journal of Infection and Public Health, (2017). When compared to Majmaah city, attitudes among school students at the primary, intermediate, and high levels were 60.84 percent, 55.62 percent, and 59.67 percent, respectively. Almansour et al. (2016). Despite differences in educational level, there was no improvement in attitude scores. However, previous adult studies have shown that food safety knowledge increases with age and practice; younger respondents have the greatest need for additional education Pinfold and Analysis (1999). According to our findings, 37.8 percent of participants looked for sensory characteristics in food when purchasing it. However, it is impossible to tell whether a food is contaminated with, say, $E$. coli. In a study conducted by Courtney et al. (2016) it was seen that students in faculties apart from science if given food safety education through courses or via extra-curricular activities it may be beneficial Courtney et al. (2016). Food safety necessitates proper handling from the point of production to the point of consumption. Even though standards in the United States are among the highest in the world, and consumer guidance on proper food handling is available through magazines, newspapers, food labels, and other sources, errors do occur Christine and Howard (2016). From the results of our study, it was also observed that there is an association between the Education of mothers and the Food Safety knowledge of participants. The $\mathrm{p}$-value of 0.033 shows that the mother's education plays a role in the food safety knowledge of university students. The study conducted by Nurcan, Ibrahim and Suzan revealed that the educational status of the mother is linked to children's eating habits Yabanci et al. (2014). in their study, it was also observed that highly educated mother's children had higher scores about healthy eating attitudes. In another study conducted by Fathea El-Nmer, Amal a Salama and Dalia Elhawary revealed that there was a highly significant correlation between father and mother's education and their children's nutritional practice ElNmer (2014). The findings in the study conducted by Sa'ed et al. (2019) support the idea that females are more informed about appropriate food handling behaviors Sa'ed et al. (2019). Foodborne illnesses cause both damages to individuals and the economy. By focusing on food safety improvements, in addition to reducing foodborne diseases, it can help in yielding economic and social benefits. Reduced health care cost, and loss of income of the affected individual, productivity improvement, decrease in the burden of country's health care sector by improved public health and finally Consumer confidence in the country's food supply leading to financial stability Food Safety (2009). Young adults engage in risky eating behaviors such as eating raw or uncooked food of animal origin, which puts them at risk for foodborne diseases. We recommend that educational materials be included in university curricula to improve students' perceptions of food hygiene. Awareness campaigns should be conducted and media and social networking applications must be actively used to enhance the student's knowledge regarding food safety and hygiene Byrd-Bred et al. (2008).

\section{Conclusions and Recommendations}

This study revealed that knowledge of food handlers and the cooker was unsatisfactory more awareness need to be created. It was also concluded that knowledge and awareness of food safety were very low. Therefore, there is an urgent need of creating awareness among cooker consumers and food handlers.

\section{Novelty Statement}

The present study will very helpful to understand, in Food Safety Knowledge.

\section{Author's Contribution}

Junaid Ahmad, Shahzeb Javed, Mehmood Khan and Shadman: Conceptualization, Methodology, Formal Analysis and Writing-original draft.

Muhammad Saleem and Rahila Afzal: Help in methodology section.

Muhammad Aasim and Naqeeb Ullah: Help in introduction section.

Shadman: Help in result section.

Muhammad Noman Khan and Dawood: Discussion section.

Muhammad Farooq and Naila Ilyas: Conceptualization, Review the manuscript \& amp; Editing.

Conflict of interest

The authors have declared no conflict of interest.

\section{References}

Abdalla, M.A., S.E.S., and Faridah, H., Ismail, C., 
Tamby, C., Rosmaliza, M., Norhayati, M.Y., 2008. Food safety knowledge and practices of mobile food vendor in Atbara city (near elneel state student). 8(24): 6966971. http;//www. academicjurnals.org/AJB

Ali, A.N., William, A.F., 2018. A KAP Study on Food Safety and Hygiene Among Private University Students in Kedah. Int. Marit. Health, 69(4): 270-277.

Almansour, M., and Sam, W., 2016. Knowledge, attitude and practice (KAP) of food hygiene among school students' in Majmaah city, Saudi Arabia.J. Pak. Med. Assoc., 66(4): 442-446.

Aluh., 2019. The knowledge and practice of food safety by young and adult consumers. International Journal of Adolescent Medicine and Health. pp. 20180252.

Byrd-Bred, B.C., Abbot, J.M., Wheatley, V., Schaffner,D.,Bruhn,C.,Blalock,L., 2008. Risky eating behavior of young adults: Implications for food safety education. J. Am. Diet Assoc., 108(3): 549-552. https://doi.org/10.1016/j. jada.2007.12.013

Cheraghi, Z., Okhovat, B., and Irani, A.D., 2014. Knowledge, attitude, and practice regarding food, and waterborne outbreak after massive diarrhea outbreak in Yazd Province, Iran, summer 2013. International Scholarly Research Notices, vol. 2014, Article ID 403058, 7 pages, 2014. https://doi.org/10.1155/2014/403058

Christine,M.B., and Schutz,H.G.,2016. Consumer food safety knowledge and practices.

Courtney, S.M., Majowicz, S.E., and Dubin, J.A., 2016. Food safety knowledge of undergraduate students at a Canadian university: results of an online survey. BMC Public Health, 16: 1147.

El-Nmer, F., Salama, A. and Elhawar, D., 2014. Nutritional knowledge, attitude, and practice of parents and its impact on growth of their children. Menoufia Med. J., 27(3): 612-616. https://doi.org/10.4103/1110-2098.145529

FAO/WHO, 2003. Codex Alimentarius, Basic Text on Food Hygiene. $3^{\text {rd }}$ ed., Italy.

Feglo, P.K. and Sakyi, K., 2012. Bacterial contamination of street vending food in Kumasi, Ghana. Journal of Medical and Biomedical Sciences, 1(1): 1-8.

Food Safety, 2009. United States Department of Agriculture, National Institute of Food and Agriculture.

Foodborne Disease Outbreaks, 2008. Guidelines for investigation and control (2008).

Hussein, F.H. and Dimassi, H., 2014. Food safety and handling knowledge and practices of Lebanese university students. Food Control, 40: 127- 133. https://doi.org/10.1016/j. foodcont.2013.11.040

Knowledge, 2014. Attitudes and practices of food handlers on food safety in food service operations at the University Kebangsaan Malaysia. Food Control, 37: 210-217. https:// doi.org/10.1016/j.foodcont.2013.09.036

Labib, S. and Al-Malkhi, T., 2010. KAP of Taif University students on food poisoning. Food Control,21(1):55-60.https://doi.org/10.1016/j. foodcont.2009.03.015

Lam, H.M., Remais, J., Fung, M.-C., Xu, L. and Sun, S.S.-M., 2013. Food supply and food safety issues in China. The Lancet, 381(9882): 2044-2053. https://doi.org/10.1016/S01406736(13)60776-X

Mallach, E., Ferrao, T., MacLean, R. and Kirk, S., 2016. Public health 2016: Time for a cultural shift in the field of public health-HPCDP: Volume 36-11, Public Health Agency of Canada reports and publications, 2016. https:// doi.org/10.24095/hpcdp.36.11.04

Mensah, P., Yeboah-Manu, D., Owusu-Darko, K., and Ablordey, A., 2002. Street foods in Accra, Ghana: How safe are they? Bulletin of the World Health Organization, 80(7): 546-554.

Nevins, S., 2003. The knowledge and practice of food safety by young and adult consumers. Food Control, 20(6): 538-542. https://doi. org/10.1016/j.foodcont.2008.08.006

Odeyemi, O.A., 2016. Public health implications of microbial food safety and foodborne diseases in developing countries. Food and Nutrition Research,60(1):29819.https://doi.org/10.3402/ fnr.v60.29819

Pinfold, J.V., 1999. Analysis of different communication channels for promoting hygiene behavior. Health Education Research, 14(5): 629639. https://doi.org/10.1093/her/14.5.629

Sa'Ed Zyoud, and Shalabi, J., 2019. Knowledge, attitude and practices among parents regarding food poisoning: a cross-sectional study from Palestine. BMC Public Health, 19(1): 586. https://doi.org/10.1186/s12889-019-6955-2

Stratev, D., Olumide, A., Odeyemib., Alexander, P., Ralica, K., Foad, F., and Florence, A.B., 2017. Food safety knowledge and hygiene practices 
among veterinarymedicine students at Trakia University, Bulgaria. Journal of Infection and Public Health. 10(2017): 778-782. https://doi. org/10.1016/j.jiph.2016.12.001

Stratev,D., Odeyemi, O.A., Pavlov, A., Kyuchukova, R., Fatehi, F. and Bamidele, F.A., 2017. Food safety knowledge and hygiene practices among veterinary medicine students at Trakia University, Bulgaria. Journal of Infection and Public Health, 10(6): 778-782.

Takeda, S., Akamatsu, R., Horiguchi, I. and Marui, E., 2011. Relationship among foodsafety knowledge, beliefs, and risk-reduction behavior in university students in Japan. Journal of Nutrition Education and Behavior, 43(6): 449-454. https://doi.org/10.1016/j. jneb.2010.08.009

WHO. 1999. Food safety: An essential public health issue for the new millennium.

Yabanci, N., Kisac, I. and Karakus, S.S., 2014. The effects of mother's nutritional knowledge on attitudes and behaviors of children about nutrition. Proc. Soc. Behav. Sci., 116(2014): 4477-4481. https://doi.org/10.1016/j. sbspro.2014.01.970 